\title{
Development and Validation of the Japanese-Translated Version of the Personal Need for Structure Scale
}

\author{
Jun Kashihara ${ }^{1,2}$ \\ ${ }^{1}$ College of Humanities and Sciences, Nihon University, Tokyo, Japan \\ ${ }^{2}$ Research Fellow of the Japan Society for the Promotion of Science, Tokyo, Japan \\ Email: better.days.ahead1121@gmail.com
}

Received 4 February 2016; accepted 27 March 2016; published 30 March 2016

Copyright (C) 2016 by author and Scientific Research Publishing Inc.

This work is licensed under the Creative Commons Attribution International License (CC BY). http://creativecommons.org/licenses/by/4.0/

C) (i) Open Access

\begin{abstract}
Personal need for structure (PNS) refers to individual differences in tendency to structure huge amounts of information into a simplified form, and was frequently examined in previous research in association with strategies for reducing cognitive load and with creativity. The present research developed a new Japanese-translated version of the PNS Scale (PNS-J) and conducted two surveys with samples of Japanese university students to validate the PNS-J. Study $1(N=244)$ examined internal consistency and factor structure of the PNS-J. Although the Response to Lack of Structure subscale and the total 11 items had sufficient internal consistency $(\alpha=.73, .76$, respectively), the Desire for Structure subscale had a smaller value for internal consistency $(\alpha=.55)$. Confirmatory factor analyses showed that the two-factor model of the PNS-J fit the data better than the one-factor model, as shown in the studies that validated the original PNS Scale. Study 2 conducted assessments at two time points (T1 and T2) to examine correlations between the PNS-J and other related variables, and to evaluate test-retest reliability of the PNS-J with a 4-week interval. Analyses using the T1 dataset $(N=354)$ provided convergent evidence of validity with big-five personality traits and discriminant evidence with need for cognition. Analyses using both the T1 and the T2 dataset $(N=$ 245) showed that both the Desire for Structure subscale $(r=.67, p<.001,95 \% \mathrm{CI}[.60, .72])$ and the Response to Lack of Structure subscale $(r=.80, p<.001,95 \% \mathrm{CI}[.76, .83])$ had acceptable test-retest reliability. These findings from the present research supported that the PNS-J was mostly comparable to the original PNS Scale. The PNS-J may contribute to future research on strategies for reducing cognitive load and on creativity in Japan, with a focus on individual differences.
\end{abstract}

\section{Keywords}

Personal Need for Structure, Validation, Personality Measures, Psychometrics, Measurement 


\section{Introduction}

Personal need for structure (PNS) refers to individual differences in tendency to structure huge amounts of information in the world into a simplified form (Neuberg \& Newsom, 1993). As implied by its definition, PNS is closely related to strategies for reducing cognitive load, such as using schemata, prototypes, and stereotypes. Previous experimental studies showed that individuals with high PNS tended to organize and simplify provided information (Moskowitz, 1993; Neuberg \& Newsom, 1993), use stereotypes (Clow \& Esses, 2005; Neuberg \& Newsom, 1993; Schaller, Boyd, Yohannes, \& Obrien, 1995), and produce illusory correlations as a result of cognitively economical heuristic processes (Gordon, 1997). It was also shown in previous surveys that PNS had positive correlations with the rigidity of one's cognition, such as dogmatism (Crowson, 2009; Neuberg \& Newsom, 1993), intolerance for ambiguity (Neuberg \& Newsom, 1993; Rubin, Paolini, \& Crisp, 2011), authoritarianism (Jugert, Cohrs, \& Duckitt, 2009; Kemmelmeier, 2010; Neuberg \& Newsom, 1993; Newheiser \& Dovidio, 2012), and intergroup disgust sensitivity (Hodson et al., 2013).

More recently, PNS has become focused on research of creativity (Gocłowska, Baas, Crisp, \& De Dreu, 2014; Gocłowska \& Crisp, 2013; Rietzschel, De Dreu, \& Nijstad, 2007; Rietzschel, Slijkhuis, \& Van Yperen, 2014; Slijkhuis, Rietzschel, \& Van Yperen, 2013). These studies especially focused on the moderating role of PNS, i.e. several studies (Gocłowska et al., 2014; Gocłowska \& Crisp, 2013; Rietzschel et al., 2014; Slijkhuis et al., 2013) reported that the strength of relations between creative performances and certain kinds of experimental tasks or situations were changed according to the participants' strength in PNS. It was reported, for example, that more creative ideas were generated after the counter-stereotypical thinking only for the participants with low PNS (Gocłowska \& Crisp, 2013), and that higher creative performances were achieved in informational evaluative situations only when the individuals' PNS was low (Slijkhuis et al., 2013). To summarize, PNS has been regarded as one of the important personality traits because of its relation to strategies for reducing cognitive load and due to its unique moderating role on research on creativity.

To assess PNS, the 11-item PNS Scale validated by Neuberg \& Newsom (1993) was widely used among self-reporting questionnaires in the previous research. The PNS Scale consists of two subscales: the Desire for Structure subscale (e.g., "I enjoy having a clear and structured mode of life," 4 items) and the Response to Lack of Structure subscale (e.g., "It upsets me to go into a situation without knowing what I can expect from it," 7 items). Neuberg \& Newsom (1993) provided several points of convergent and discriminant evidence and showed that both subscales had sufficient test-retest reliability with a 12-week interval ( $r=.84$ for the Desire for Structure subscale, $r=.79$ for the Response to Lack of Structure subscale). Although the original PNS Scale was written in English, the use of the PNS Scale has become widespread in non-native English-speaking countries as well. The PNS Scale was translated into languages such as German (Machunsky \& Meiser, 2006), Dutch (Rietzschel et al., 2007), and Chinese (Shi, Wang, \& Chen, 2009), and validation of these translated versions were conducted in each country.

However, to the best of the author's knowledge, there exists no Japanese-translated version of the PNS Scale that is comparable to the original version. Although Suzuki \& Sakurai (1999) tried developing a Japanese version, they did not follow appropriate translation back-translation steps and changed the contents of some items without permission of the authors of the original PNS Scale. Moreover, Suzuki \& Sakurai (1999) reduced the number of items of the PNS Scale from 11 to 10; therefore, the Japanese version they developed is not regarded as comparable to the original version. To accelerate the research on PNS in Japan and to explore cultural differences and universalities of PNS, it is indispensable to develop a new Japanese-translated version that is comparable to the original PNS Scale.

Given these considerations, the present research developed a new Japanese version of the PNS Scale (PNS-J) and conducted its validation with samples of Japanese university students to accumulate evidence that the PNS-J is comparable to the original PNS Scale. Study 1 developed the PNS-J by following translation back-translation steps and examined its internal consistency and factor structure. Study 2 examined correlation between the PNS$\mathrm{J}$ and other related variables (big-five personality traits and need for cognition) to show convergent and discriminant evidence of validity of the PNS-J, and evaluated test-retest reliability of the scale.

\section{Study 1}

\subsection{Objective}

As mentioned above, Study 1 developed the PNS-J and conducted its initial validation. Internal consistency of 
the scale was evaluated, and confirmatory factor analyses were conducted to examine if the two-factor structure of the original PNS Scale was maintained in the PNS-J.

\subsection{Method}

\subsubsection{Participants}

The participants were 244 Japanese undergraduate students (165 female and 77 male; 2 participants did not indicate gender) who attended introductory psychology classes at three universities in the Kanto district in Japan. The mean age of the participants was $21.10(S D=2.45)$ years.

\subsubsection{Procedure}

The procedure used in Study 1 was approved by the Office for Life Science Research Ethics and Safety at the University of Tokyo (reference number: 14 - 124). The questionnaires were distributed to the participants at the end of each of the classes. All participants were informed of the purpose of the study and told that they could withdraw their participation at any time. They were also informed that by submitting the questionnaires they would consent to participation in the study. All data were collected and analyzed anonymously. No monetary reward was given for participation.

\subsubsection{Measures}

The original PNS Scale that was validated by Neuberg \& Newsom (1993) was translated by following translation back-translation steps in order to keep the semantic equivalence between the original and the translated versions. First, the author of the present research translated the original English version into Japanese. Then, a bilingual collaborator back-translated the Japanese draft made by the author into English. Next, another bilingual collaborator compared the original and back-translated versions to check if these versions were semantically equivalent and commented where there were differences in some items. Afterward, the author of the present studies corrected some phrases used in the Japanese draft based on the comments by the second collaborator. Finally, the second collaborator guaranteed that the resulting Japanese version (PNS-J) was semantically equivalent to the original version.

The PNS-J used a 7-point Likert scale with the anchors 1: strongly disagree to 4: neither agree nor disagree to 7: strongly agree. The 11 items of the original PNS Scale are shown in Appendix section. ${ }^{1}$

\subsubsection{Data Analysis}

Amos version 22 and Stata version 14 were used to analyze the data. First, the amount of missing values was examined. Then, Cronbach's $\alpha$ coefficients were calculated to examine internal consistency of the PNS-J. Afterward, confirmatory factor analyses using the 11 items of the PNS-J as indicators were performed to examine whether the two-factor model -4 items loaded on the Desire for Structure factor and the other 7 items loaded on the Response to Lack of Structure factor-fits the data better than the one-factor model. Additionally, confirmatory factor analyses using parceling techniques, which aggregate several items into parcels, were performed. In general, model fit indexes in confirmatory factor analyses become worse as indicators of latent variables increase (Bandalos, 2002; Coffman \& MacCallum, 2005; Gribbons \& Hocevar, 1998; Little, Cunningham, Shahar, \& Widaman, 2002; Marsh, Hau, Balla, \& Grayson, 1998). Even if the one-factor model using the 11 items as indicators fit worse than the two-factor model with the data in Study 1, it is possible that these results were due not to the superiority of the two-factor model, but due to using too many indicators in the one-factor model. Although there are some criticisms of using parceling techniques (see Little et al., 2002, for a review), showing that the one-factor model fit worse than the data, with or without the use of item parceling, would be stronger evidence for supporting the two-factor structure of the PNS-J. Based on the recommendation by Jackson, Gillaspy, \& Purc-Stephenson (2009), Study 1 evaluated each model with multiple and different types of model fit indexes: The Tucker-Lewis index (TLI), the comparative fit index (CFI), and the root mean square error of approximation (RMSEA).

\subsection{Results}

\subsubsection{Amount of Missing Values}

Two values (.82\% among 244 participants) of item 6 were missing, and all of the other values of the PNS-J were

${ }^{1}$ The author is glad to share the 11 items translated into Japanese upon request. 
observed. The pattern of the missing values was considered as Missing at Random (see Acock, 2005; Rubin, 1976; Schlomer, Bauman, \& Card, 2010, for details about patterns of missing values). Full information maximum likelihood estimation, which is one of the most recommended procedures for handling missing values with the pattern of Missing at Random (see Schlomer et al., 2010, for a simulation study), was used in subsequent analyses.

\subsubsection{Descriptive Statistics and Internal Consistency}

Descriptive statistics and Cronbach's $\alpha$ coefficients were summarized in Table 1. These results showed the Response to Lack of Structure subscale and the total 11 items had sufficient internal consistency $(\alpha=.73$, .76, respectively). For the Desire for Structure subscale, on the other hand, a smaller value for internal consistency was obtained $(\alpha=.55)$.

\subsubsection{Factor Structure}

The results of confirmatory factor analyses without item parceling were summarized in Table 2. As shown in Table 2, the two-factor model $\left(\chi^{2}(43)=75.77, p=.001\right.$, CFI $=.922$, TLI $=.881$, RMSEA $\left.=.056\right)$ fit the data better than the one-factor model $\left(\chi^{2}(44)=108.09, p<.001\right.$, CFI $=.848$, TLI $=.772$, RMSEA $\left.=.077\right)$.

The results of confirmatory factor analyses using item parceling techniques were also summarized in Table 2. In the one-factor model, 11 items of the PNS-J were randomly assigned to 4 parcels. Four parcels were chosen since models with 3 indicators loaded on one factor generally become saturated models and cannot be evaluated by model fit indexes. Parcel 1 comprised of items 1, 6, and 7; parcel 2 comprised of items 3, 4, and 8; parcel 3 comprised of items 5, 9, and 11; and parcel 4 comprised of items 2 and 10. In the two-factor model, items were randomly assigned to 3 parcels within each of the Desire for Structure and the Response to Lack of Structure subscales as displayed in Figure 1. As shown in Table 2, the two-factor model $\left(\chi^{2}(8)=10.44, p=.235\right.$, CFI $=.992, \mathrm{TLI}=.978, \mathrm{RMSEA}=.035)$ fit the data better than the one-factor model $\left(\chi^{2}(2)=8.44, p=.015\right.$, CFI $=.967$, TLI $=.833$, RMSEA $=.115)$, as was also the case for confirmatory factor analyses without parcels. Moreover, the two-factor model using item parceling techniques met all cutoff criteria (CFI > .95, TLI > .95, RMSEA < .06) proposed by Hu \& Bentler (1999). The standardized factor loadings obtained in the two-factor model using item parceling techniques are displayed in Figure 1.

Table 1. Descriptive statistics and Cronbach's $\alpha$ coefficients for the PNS-J.

\begin{tabular}{ccccc}
\hline & Items & $M$ & $S D$ & $\alpha$ \\
\hline Desire for structure subscale & 4 & 4.02 & .96 & .55 \\
Response to lack of structure subscale & 7 & 4.36 & .94 & .73 \\
Total & 11 & 4.23 & .81 & .76 \\
\hline
\end{tabular}

Note: Calculated averages of the items. Scores ranged from 1: strongly disagree to 4: neither agree nor disagree to 7: strongly agree.

Table 2. Fit indexes for different models of the PNS-J.

\begin{tabular}{ccccccc}
\hline Model & $\chi^{2}$ & $d f$ & $p$ & CFI & TLI & RMSEA \\
\hline One-factor, without item parceling & 108.09 & 44 & $<.001$ & .848 & .772 & .077 \\
Two-factor, without item parceling & 75.77 & 43 & .001 & .922 & .881 & .056 \\
One-factor, with item parceling & 8.44 & 2 & .015 & .967 & .833 & .115 \\
Two-factor, with item parceling & 10.44 & 8 & .235 & .992 & .978 & .035 \\
\hline
\end{tabular}

Note: CFI = comparative fit index; TLI = Tucker-Lewis index; RMSEA = root mean square error of approximation. 


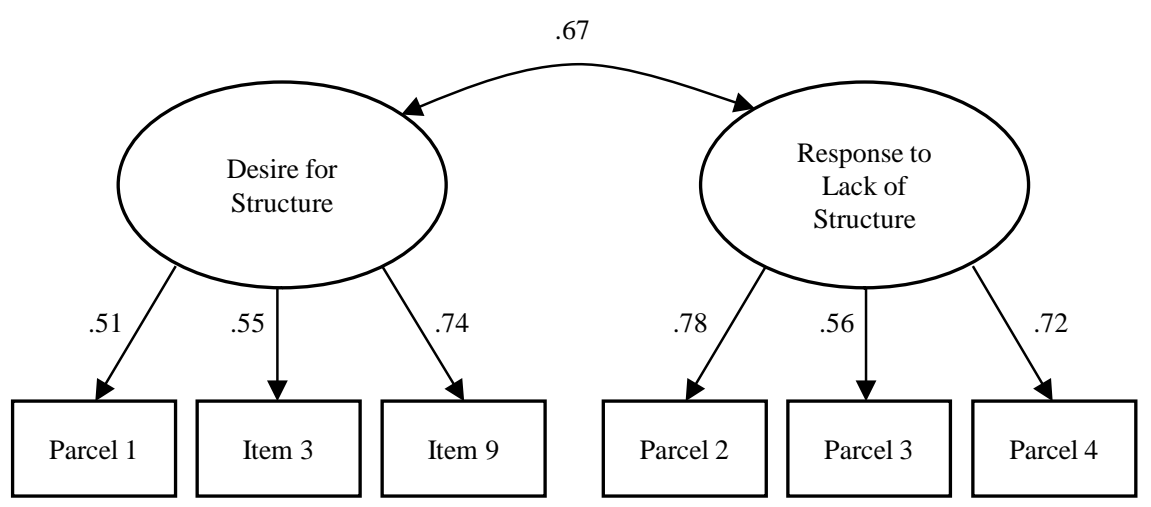

Figure 1. The two-factor model of the PNS-J using parceling techniques. Items were randomly assigned to 3 parcels within each of the Desire for Structure and the Response to Lack of Structure subscales. Parcel $1=$ an average of items 4 and 5; Parcel $2=$ an average of items 1, 6, and 7; Parcel $3=$ an average of items 2 and 10; Parcel $4=$ an average of items 8 and 11. Standardized coefficients are reported. Errors for each parcel are not displayed in order to keep the figure simple.

\subsection{Discussion}

The results of confirmatory factor analyses revealed that the two-factor model of the PNS-J fit better than the one-factor model, regardless of whether using items or parcels as indicators. Moreover, confirmatory factor analyses using parcels revealed that the two-factor model met all cutoff criteria (CFI > .95, TLI > .95, RMSEA $<$.06) proposed by Hu \& Bentler (1999). These findings strongly supported that the two-factor structure of the original PNS Scale was maintained in the PNS-J.

On the other hand, it cannot be concluded from the results of Study 1 whether the PNS-J had sufficient reliability. Although Cronbach's $\alpha$ coefficients showed sufficient internal consistency for the Response to Lack of Structure subscale $(\alpha=.73)$ and the total 11 items $(\alpha=.76)$, the Desire for Structure subscale had a smaller $\alpha$ coefficient $(\alpha=.55)$. Considering that the Desire for Structure subscale with only 4 items included a variety of contents and a reverse-scored item (see Appendix for the items of the original PNS Scale), this small value of the $\alpha$ coefficient possibly reflected the large unique variance of items. In order to discuss the reliability of the Desire for Structure subscale more rigorously, it is necessary to add criteria other than internal consistency for evaluation of the reliability of the scale. The evaluation of the test-retest reliability of the subscales of the PNS-J was therefore conducted as a part of Study 2.

\section{Study 2}

\subsection{Objective}

Study 2 conducted further validation of the PNS-J developed in Study 1. First, Study 2 examined correlations between the PNS-J and other related variables to provide convergent and discriminant evidence of validity of the PNS-J. Second, test-retest reliability of the PNS-J measure was examined with a 4-week interval.

\subsection{Method}

\subsubsection{Participants}

The participants at the baseline assessment (T1) were 354 Japanese undergraduate students (216 female and 137 male; 1 participant did not indicate gender) who attended introductory psychology classes at three universities in Tokyo. The mean age of the participants at $\mathrm{T} 1$ was $20.17(S D=2.02)$ years. Two hundred and forty-five of them (166 female and 78 male; 1 participant did not indicate gender) submitted the questionnaires at the second assessment (T2) as well. The mean age of the participants at T2 was $20.24(S D=2.33)$ years.

\subsubsection{Procedure}

The procedure used in Study 2 was approved by the Office for Life Science Research Ethics and Safety at the 
University of Tokyo (reference number: 14 - 166). The first questionnaires were distributed to the participants at the end of each of the classes (T1), and the second questionnaires were distributed to the participants 4 weeks after T1 at the end of the same classes (T2). All participants were informed of the purpose of the study and told that they could withdraw their participation at any time. They were also informed that by returning the questionnaires they would consent to participation in the study. The participants wrote their birthdates and the last four digits of their cell phones on the questionnaires in order to connect data collected at T1 and T2. All data were collected and analyzed anonymously. No monetary reward was given for participation.

\subsubsection{Measures}

To show convergent evidence of validity of the PNS-J, big-five personality traits were assessed. Big-five personality traits refer to extraversion, agreeableness, conscientiousness, neuroticism, and openness, which were defined as five fundamental personality traits in previous quantitative studies (Goldberg, 1990, 1992). Validation studies of the original (Neuberg \& Newsom, 1993) and the Chinese (Shi et al., 2009) versions of the PNS Scale consistently reported following results: the Desire for Structure subscale positively correlated with Conscientiousness subscale $(r s=.35-.41)$; the Response to Lack of Structure subscale negatively correlated with the Extraversion ( $r \mathrm{~s}=-.23--.18$ ) and Openness subscales $(r \mathrm{~s}=-.44--.41)$, and positively correlated with the Neuroticism subscale ( $r s=.31-.32$ ). It is therefore desirable that the pattern of correlation between PNS and big-five personality traits would be replicated in the present study. Although the validation study of the original PNS Scale (Neuberg \& Newsom, 1993) also reported that the two subscales of the PNS Scale positively correlated with variables that are related to the rigidity of one's cognition-such as dogmatism (Rokeach, 1960) and intolerance of ambiguity (Eysenck, 1954)—the present study did not assess these measures considering that there exist no Japanese measures of these constructs that replicated the factor structures of the original measures.

Big-five personality traits were assessed using the Japanese version (Oshio, Abe, \& Cutrone, 2012) of the Ten-Item Personality Inventory (Gosling, Rentfrow, \& Swann, 2003). The original Ten-Item Personality Inventory (Gosling et al., 2003) was developed as a brief measure of big-five personality traits, which assess each trait (extraversion, agreeableness, conscientiousness, neuroticism, and openness) with 2 items. Oshio et al. (2012) developed the Japanese version by following translation back-translation steps and showed a sufficient test-retest reliability with a 12-week interval and moderate to strong correlations between traditional measures of big-five personality traits such as the NEO Five-Factor Inventory (Costa \& McCrae, 1992).

To show discriminant evidence of validity of the PNS-J, need for cognition was assessed. Need for cognition refers to individual differences in tendency to engage in or enjoy cognitively demanding activities (Cacioppo \& Petty, 1982). Although both PNS and need for cognition are related to thinking or cognitive activities, PNS refers to individual differences in tendency to structure information (Neuberg \& Newsom, 1993) and does not imply whether individuals enjoy cognitive activities or not. Validation studies of the original (Neuberg \& Newsom, 1993) and the Chinese (Shi et al., 2009) versions of the PNS Scale reported weak and inconsistent correlations between the PNS subscales and need for cognition $(r s=-.11-.20$ for the Desire for Structure subscale, $r$ s $=-.27-.02$ for the Response to Lack of Structure subscale). Although values of correlation coefficients vary across samples in studies, it is desirable that the subscales of the PNS-J would not strongly correlate with need for cognition. The assessment of need for cognition was administered using the Japanese version (Kouyama \& Fujihara, 1991) of the Need for Cognition Scale (Cacioppo \& Petty, 1982). Kouyama \& Fujihara (1991) translated the original 34-item measure (Cacioppo \& Petty, 1982) into Japanese and developed a short-form measure of need for cognition which includes 15 items. Kouyama \& Fujihara (1991) showed that the Japanese version had one-factor structure as well as the original version (Cacioppo \& Petty, 1982) and indicated that the Japanese and the original version were comparable.

The PNS-J and the Japanese versions of the Ten-Item Personality Inventory and the Need for Cognition Scale were administered at T1 and T2. Each measure used a 7-point Likert scale with the anchors 1: strongly disagree to 4: neither agree nor disagree to 7: strongly agree.

\subsubsection{Data Analysis}

All analyses were performed with Stata version 14. First, the amount of missing values was examined. Then, correlation between the PNS-J and the other measures were examined based on the T1 dataset. Afterward, test-retest reliability regarding the subscales of the PNS-J was examined based on the dataset of who participated at both $\mathrm{T} 1$ and $\mathrm{T} 2$. 


\subsection{Results and Discussion}

\subsubsection{Amount of Missing Values}

The percentages of missing values ranged from $.00 \%$ to $2.26 \%$ for each variable among the T1 dataset, and ranged from $.00 \%$ to $.82 \%$ for the PNS-J among the dataset of who participated at both T1 and T2. The pattern of missing values was considered as Missing at Random. The multiple imputation procedure, which is one of the most recommended procedures to deal with missing values with the pattern of Missing at Random (see Schlomer et al., 2010, for a simulation study), was used to handle missing values. Based on each individual dataset, 20 imputed datasets were generated using the mvis command for Stata (Royston, 2004) to obtain the results.

\subsubsection{Correlations between the PNS-J and the Other Measures}

Correlations between measures were summarized in Table 3. As expected, the Desire for Structure subscale positively correlated with the Conscientiousness subscale $(r=.24, p<.001,95 \%$ CI [.13, .33]) and did not significantly correlate with the Need for Cognition scale $(r=-.02, p=.655,95 \% \mathrm{CI}[-.13, .08])$. As also expected, the Response to Lack of Structure subscale negatively correlated with the Extraversion $(r=-.25, p<.001,95 \%$ CI $[-.35,-.15])$, Openness subscales $(r=-.22, p<.001,95 \%$ CI $[-.31,-.12])$, and positively correlated with the Neuroticism subscale $(r=.28, p<.001,95 \%$ CI [.18, .37]). Although the Response to Lack of Structure subscale significantly correlated with the Japanese version of the Need for Cognition Scale, the correlation was relatively weak ( $r=-.15, p=.005,95 \%$ CI $[-.25,-.05])$. To summarize, the PNS-J replicated the pattern of correlation reported in previous studies (Neuberg \& Newsom, 1993; Shi et al., 2009).

\subsubsection{Test-Retest Reliability}

The correlation coefficient between scores at T1 and T2 was $r=.67(p<.001,95 \%$ CI $[.60, .72])$ for the Desire for Structure subscale and was $r=.80(p<.001,95 \%$ CI [.76, .83]) for the Response to Lack of Structure subscale. Although the correlation coefficient for the Desire for Structure subscale was slightly weaker than that of the Response to Lack of Structure subscale, each subscale was considered as having sufficient test-retest reliability with a 4-week interval.

\section{General Discussion}

The present research comprised of two studies that aimed to develop and validate a new Japanese version of the PNS Scale (PNS-J). As shown above, these studies provided several points of validity evidence of the PNS-J.

Table 3. Correlations of the PNS-J with other measures.

\begin{tabular}{|c|c|c|c|c|c|c|c|c|}
\hline Model & 1 & 2 & 3 & 4 & 5 & 6 & 7 & 8 \\
\hline 1) PNS: Desire for structure & - & & & & & & & \\
\hline 2) PNS: Response to lack of structure & $.47^{* * *}$ & - & & & & & & \\
\hline 3) Big-Five Personality: Extraversion & $-.18^{* * *}$ & $-.25^{* * *}$ & - & & & & & \\
\hline 4) Big-Five Personality: Agreeableness & -.05 & -.08 & -.01 & - & & & & \\
\hline 5) Big-Five Personality: Conscientiousness & $.24^{* * * *}$ & $.23^{* * *}$ & .07 & $.12^{*}$ & - & & & \\
\hline 6) Big-Five Personality: Neuroticism & $.14^{* *}$ & $.28^{* * *}$ & $-.12 *$ & $-.16^{* *}$ & -.06 & - & & \\
\hline 7) Big-Five Personality: Openness & $-.11^{*}$ & $-.22^{* * *}$ & $.33^{* * *}$ & .03 & .10 & -.09 & - & \\
\hline 8) Need for Cognition & -.02 & $-.15^{* *}$ & $.16^{* *}$ & .10 & $.22^{* * * *}$ & -.06 & $.35^{* * *}$ & - \\
\hline$M$ & 3.80 & 4.35 & 3.79 & 4.78 & 3.12 & 4.75 & 3.93 & 4.01 \\
\hline$S D$ & 1.01 & 1.01 & 1.39 & 1.09 & 1.19 & 1.09 & 1.31 & .86 \\
\hline$\alpha$ & .57 & .74 & - & - & - & - & - & .85 \\
\hline
\end{tabular}

Note: PNS = personal need for structure. Calculated averages of the items. Scores ranged from 1: strongly disagree to 4: neither agree nor disagree to 7: strongly agree. In regard to the subscales of big-five personality traits, Cronbach's $\alpha$ coefficients for were not calculated; Cronbach's $\alpha$ coefficients were considered as inappropriate indexes for evaluating internal consistency as each subscale assessed broad constructs with only 2 items (see Gosling et al., 2003 for a more detailed discussion). ${ }^{*} p<.05$. $^{* *} p<.01 .{ }^{* * *} p<.001$. 
The two-factor structure of the original PNS Scale (Neuberg \& Newsom, 1993)—consisting of the Desire for Structure and the Response to Lack of Structure subscales-are replicated in Study 1. In Study 2, convergent evidence was obtained with big-five personality traits, and discriminant evidence was found with need for cognition. Concerning reliability of the PNS-J, the following findings were obtained: the Response to Lack of Structure subscale had sufficient internal consistency (Study $1 ; \alpha=.73$ ) and test-retest reliability (Study 2; $r$ $=.80, p<.001,95 \%$ CI $[.76, .83])$; although internal consistency for the Desire for Structure subscale was low (Study 1; $\alpha=.55$ ), test-retest reliability for this subscale was acceptable (Study 2; $r=.67, p<.001$, 95\% CI $[.60, .72])$. Considering that test-retest reliability of the Desire for Structure subscale was acceptable, it seems that low internal consistency was not due mainly to large measurement error of the subscale, but due rather to the large unique variance of items. Given the low internal consistency, it is advisable not to use an average score of the items of the Desire for Structure subscale in statistical analyses, but instead to use the items as indicators of a latent variable.

\section{Limitations}

Several limitations should be highlighted in the present research. First, the samples used in the present research are limited to university students. It is therefore uncertain from the present research whether the PNS-J is applicable to a broader population in Japan. Future research should use more diverse samples in terms of age and occupation in order to confirm if the results of the present research would be replicated.

Second, the present research examined correlations of the PNS-J with a limited number of variables (big-five personality traits and need for cognition), because there exists no Japanese measures of constructs such as dogmatism and intolerance of ambiguity that replicated the factor structures of the original measures. Japanese measures of these PNS-related constructs should be developed in the future by following strict validation processes in order to accumulate more points of convergent and discriminant evidence of validity of the PNS-J.

Third, the present research conducted validation of the PNS-J only by cross-sectional surveys. Although previous experimental studies showed the predicting role of PNS in relation to strategies for reducing cognitive load (Clow \& Esses, 2005; Gordon, 1997; Moskowitz, 1993; Neuberg \& Newsom, 1993; Schaller et al., 1995) and the moderating role of PNS concerning creativity (Gocłowska et al., 2014; Gocłowska \& Crisp, 2013; Rietzschel et al., 2014; Slijkhuis et al., 2013), it is uncertain from the present research whether these predicting and moderating roles can be observed by using the PNS-J. Application of the PNS-J is therefore desirable in future experimental studies that test hypotheses of the predicting or moderating roles of PNS.

\section{Conclusion}

Despite these limitations, findings from the present research supported that the PNS-J was mostly comparable to the original PNS Scale. The PNS-J may accelerate international comparison research that includes Japan and focuses on PNS. Moreover, the PNS-J may contribute to future research on strategies for reducing cognitive load and on creativity in Japan, especially with those that focus on individual differences. Future research in Japan should implement a wide range of application of the PNS-J and conduct further validation of the scale to overcome the limitations noted above.

\section{Acknowledgements}

The author wishes to thank Aiko Komoto and Ayako Shimizu for their help with translation, and Brian Berry for English proof reading. Financial disclosures: the author has no conflict of interest to declare.

\section{References}

Acock, A. C. (2005). Working with Missing Values. Journal of Marriage and Family, 67, 1012-1028. http://dx.doi.org/10.1111/j.1741-3737.2005.00191.x

Bandalos, D. L. (2002). The Effects of Item Parceling on Goodness-of-Fit and Parameter Estimate Bias in Structural Equation Modeling. Structural Equation Modeling, 9, 78-102. http://dx.doi.org/10.1207/S15328007SEM0901_5

Cacioppo, J. T., \& Petty, R. E. (1982). The Need for Cognition. Journal of Personality and Social Psychology, 42, $116-131$. http://dx.doi.org/10.1037/0022-3514.42.1.116

Clow, K. A., \& Esses, V. M. (2005). The Development of Group Stereotypes from Descriptions of Group Members: An In- 
dividual Difference Approach. Group Processes \& Intergroup Relations, 8, 429-445.

http://dx.doi.org/10.1177/1368430205056469

Coffman, D. L., \& MacCallum, R. C. (2005). Using Parcels to Convert Path Analysis Models into Latent Variable Models. Multivariate Behavioral Research, 40, 235-259. http://dx.doi.org/10.1207/s15327906mbr4002_4

Costa, P. T., \& McCrae, R. R. (1992). Revised NEO Personality Inventory (NEO-PI-R) and NEO Five-Factor Inventory (NEO-FFI) Professional Manual. Odessa: Psychological Assessment Resources.

Crowson, H. M. (2009). Does the DOG Scale Measure Dogmatism? Another Look at Construct Validity. Journal of Social Psychology, 149, 365-383. http://dx.doi.org/10.3200/SOCP.149.3.365-383

Eysenck, E. J. (1954). The Psychology of Politics. London: Routledge \& Kegan Paul.

Gocłowska, M. A., Baas, M., Crisp, R. J., \& De Dreu, C. K. W. (2014). Whether Social Schema Violations Help or Hurt Creativity Depends on Need for Structure. Personality and Social Psychology Bulletin, 40, 959-971. http://dx.doi.org/10.1177/0146167214533132

Gocłowska, M. A., \& Crisp, R. J. (2013). On Counter-Stereotypes and Creative Cognition: When Interventions for Reducing Prejudice Can Boost Divergent Thinking. Thinking Skills and Creativity, 8, 72-79.

http://dx.doi.org/10.1016/j.tsc.2012.07.001

Goldberg, L. R. (1990). An Alternative "Description of Personality”: The Big-5 Factor Structure. Journal of Personality and Social Psychology, 59, 1216-1229. http://dx.doi.org/10.1037/0022-3514.59.6.1216

Goldberg, L. R. (1992). The Development of Markers for the Big-Five Factor Structure. Psychological Assessment, 4, $26-42$. http://dx.doi.org/10.1037/1040-3590.4.1.26

Gordon, R. A. (1997). The Moderation of Distinctiveness-Based Illusory Correlation: The Impact of Circadian Variations and Personal Need for Structure. Journal of Social Psychology, 137, 514-526. http://dx.doi.org/10.1080/00224549709595469

Gosling, S. D., Rentfrow, P. J., \& Swann, W. B. (2003). A Very Brief Measure of the Big-Five Personality Domains. Journal of Research in Personality, 37, 504-528. http://dx.doi.org/10.1016/S0092-6566(03)00046-1

Gribbons, B. C., \& Hocevar, D. (1998). Levels of Aggregation in Higher Level Confirmatory Factor Analysis: Application for Academic Self-Concept. Structural Equation Modeling, 5, 377-390. http://dx.doi.org/10.1080/10705519809540113

Hodson, G., Choma, B. L., Boisvert, J., Hafer, C. L., MacInnis, C. C., \& Costello, K. (2013). The Role of Intergroup Disgust in Predicting Negative Outgroup Evaluations. Journal of Experimental Social Psychology, 49, 195-205. http://dx.doi.org/10.1016/j.jesp.2012.11.002

Hu, L. T., \& Bentler, P. M. (1999). Cutoff Criteria for Fit Indexes in Covariance Structure Analysis: Conventional Criteria versus New Alternatives. Structural Equation Modeling, 6, 1-55. http://dx.doi.org/10.1080/10705519909540118

Jackson, D. L., Gillaspy, J. A., \& Purc-Stephenson, R. (2009). Reporting Practices in Confirmatory Factor Analysis: An Overview and Some Recommendations. Psychological Methods, 14, 6-23. http://dx.doi.org/10.1037/a0014694

Jugert, P., Cohrs, J. C., \& Duckitt, J. (2009). Inter- and Intrapersonal Processes Underlying Authoritarianism: The Role of Social Conformity and Personal Need for Structure. European Journal of Personality, 23, 607-621. http://dx.doi.org/10.1002/per.735

Kemmelmeier, M. (2010). Authoritarianism and Its Relationship with Intuitive-Experiential Cognitive Style and Heuristic Processing. Personality and Individual Differences, 48, 44-48. http://dx.doi.org/10.1016/j.paid.2009.08.012

Kouyama, T., \& Fujihara, T. (1991). A Basic Study of the Need for Cognition Scale. Japanese Journal of Social Psychology, 6, 184-192. (In Japanese with English Abstract)

Little, T. D., Cunningham, W. A., Shahar, G., \& Widaman, K. F. (2002). To Parcel or Not to Parcel: Exploring the Question, Weighing the Merits. Structural Equation Modeling, 9, 151-173. http://dx.doi.org/10.1207/S15328007SEM0902_1

Machunsky, M., \& Meiser, T. (2006). Personal Need for Structure as a Construct of Dispositional Differences in Social Psychology: Psychometric Analysis and Validation of a German PNS Scale. Zeitschrift für Sozialpsychologie, 37, 87-97. http://dx.doi.org/10.1024/0044-3514.37.2.87

Marsh, H. W., Hau, K. T., Balla, J. R., \& Grayson, D. (1998). Is More Ever Too Much? The Number of Indicators per Factor in Confirmatory Factor Analysis. Multivariate Behavioral Research, 33, 181-220. http://dx.doi.org/10.1207/s15327906mbr3302_1

Moskowitz, G. B. (1993). Individual Differences in Social Categorization: The Influence of Personal Need for Structure on Spontaneous Trait Inferences. Journal of Personality and Social Psychology, 65, 132-142. http://dx.doi.org/10.1037/0022-3514.65.1.132

Neuberg, S. L., \& Newsom, J. T. (1993). Personal Need for Structure: Individual Differences in the Desire for Simple Structure. Journal of Personality and Social Psychology, 65, 113-131. http://dx.doi.org/10.1037/0022-3514.65.1.113 
Newheiser, A. K., \& Dovidio, J. F. (2012). Individual Differences and Intergroup Bias: Divergent Dynamics Associated with Prejudice and Stereotyping. Personality and Individual Differences, 53, 70-74. http://dx.doi.org/10.1016/j.paid.2012.02.024

Oshio, A., Abe, S., \& Cutrone, P. (2012). Development, Reliability, and Validity of the Japanese Version of Ten Item Personality Inventory (TIPI-J). Japanese Journal of Personality, 21, 40-52. (In Japanese with English abstract) http://dx.doi.org/10.2132/personality.21.40

Rietzschel, E. F., De Dreu, C. K. W., \& Nijstad, B. A. (2007). Personal Need for Structure and Creative Performance: The Moderating Influence of Fear of Invalidity. Personality and Social Psychology Bulletin, 33, 855-866. http://dx.doi.org/10.1177/0146167207301017

Rietzschel, E. F., Slijkhuis, J. M., \& Van Yperen, N. W. (2014). Task Structure, Need for Structure, and Creativity. European Journal of Social Psychology, 44, 386-399. http://dx.doi.org/10.1002/ejsp.2024

Rokeach, M. (1960). The Open and Closed Mind: Investigations into the Nature of Belief Systems and Personality Systems. New York: Basic Books.

Royston, P. (2004). Multiple Imputation of Missing Values. Stata Journal, 4, 227-241.

Rubin, D. B. (1976). Inference and Missing Data. Biometrika, 63, 581-590. http://dx.doi.org/10.1093/biomet/63.3.581

Rubin, M., Paolini, S., \& Crisp, R. J. (2011). The Relationship between the Need for Closure and Deviant Bias: An Investigation of Generality and Process. International Journal of Psychology, 46, 206-213. http://dx.doi.org/10.1080/00207594.2010.537660

Schaller, M., Boyd, C., Yohannes, J., \& Obrien, M. (1995). The Prejudiced Personality Revisited: Personal Need for Structure and Formation of Erroneous Group Stereotypes. Journal of Personality and Social Psychology, 68, 544-555. http://dx.doi.org/10.1037/0022-3514.68.3.544

Schlomer, G. L., Bauman, S., \& Card, N. A. (2010). Best Practices for Missing Data Management in Counseling Psychology. Journal of Counseling Psychology, 57, 1-10. http://dx.doi.org/10.1037/a0018082

Shi, J., Wang, L., \& Chen, Y. (2009). Validation of the Personal Need for Structure Scale in Chinese. Psychological Reports, 105, 235-244. http://dx.doi.org/10.2466/PR0.105.1.235-244

Slijkhuis, J. M., Rietzschel, E. F., \& Van Yperen, N. W. (2013). How Evaluation and Need for Structure Affect Motivation and Creativity. European Journal of Work and Organizational Psychology, 22, 15-25. http://dx.doi.org/10.1080/1359432X.2011.626244

Suzuki, K., \& Sakurai, S. (1999). Construction of Japanese version of Cognitive Need for Structure Scale. Tsukuba Psychological Research, 21, 135-140. (In Japanese with English Abstract) 


\section{Appendix}

The Items of the Original PNS Scale Validated by Neuberg \& Newsom (1993)

1) It upsets me to go into a situation without knowing what I can expect from it.

2) I'm not bothered by things that interrupt my daily routine.*

3) I enjoy having a clear and structured mode of life.

4) I like to have a place for everything and everything in its place.

5) I find that a well-ordered life with regular hours makes my life tedious. ${ }^{*}$

6) I don't like situations that are uncertain.

7) I hate to change my plans at the last minute.

8) I hate to be with people who are unpredictable.

9) I find that a consistent routine enables me to enjoy life more.

10) I enjoy the exhilaration of being in unpredictable situations.

11) I become uncomfortable when the rules in a situation are not clear.

Note: The Desire for Structure subscale included items 3, 4, 5, and 9, and the Response to Lack of Structure subscale included items $1,2,6,7,8,10$, and 11 . This measure used a 7-point Likert scale with the anchors 1 : strongly disagree to 4: neither agree nor disagree to 7: strongly agree. ${ }^{*}$ Reverse-scored item. 